\title{
Subclinical dissociation, schizotypy and traumatic distress
}

Citation for published version (APA):

Merckelbach, H. L. G. J., \& Giesbrecht, T. M. (2006). Subclinical dissociation, schizotypy and traumatic distress. Personality and Individual Differences, 40(2), 365-374. https://doi.org/10.1016/j.paid.2005.07.007

Document status and date:

Published: 01/01/2006

DOI:

10.1016/j.paid.2005.07.007

Document Version:

Publisher's PDF, also known as Version of record

\section{Please check the document version of this publication:}

- A submitted manuscript is the version of the article upon submission and before peer-review. There can be important differences between the submitted version and the official published version of record.

People interested in the research are advised to contact the author for the final version of the publication, or visit the DOI to the publisher's website.

- The final author version and the galley proof are versions of the publication after peer review.

- The final published version features the final layout of the paper including the volume, issue and page numbers.

Link to publication

\footnotetext{
General rights rights.

- You may freely distribute the URL identifying the publication in the public portal. please follow below link for the End User Agreement:

www.umlib.nl/taverne-license

Take down policy

If you believe that this document breaches copyright please contact us at:

repository@maastrichtuniversity.nl

providing details and we will investigate your claim.
}

Copyright and moral rights for the publications made accessible in the public portal are retained by the authors and/or other copyright owners and it is a condition of accessing publications that users recognise and abide by the legal requirements associated with these

- Users may download and print one copy of any publication from the public portal for the purpose of private study or research.

- You may not further distribute the material or use it for any profit-making activity or commercial gain

If the publication is distributed under the terms of Article $25 \mathrm{fa}$ of the Dutch Copyright Act, indicated by the "Taverne" license above, 


\title{
Subclinical dissociation, schizotypy, and traumatic distress
}

\author{
Harald Merckelbach *, Timo Giesbrecht \\ Department of Experimental Psychology, Maastricht University, P.O. Box 616, \\ 6200 MD, Maastricht, The Netherlands
}

Received 7 May 2005; received in revised form 4 July 2005; accepted 26 July 2005

Available online 9 September 2005

\begin{abstract}
The current study looked at the overlap between dissociation and schizotypy and examined two potential sources from which this overlap might originate: fantasy proneness and traumatic distress. From a sample of 191 undergraduates, those scoring in the upper and lower quartile of the Dissociative Experiences Scale (DES) were selected. Next, the scores of these groups on well-established schizotypy scales were compared to each other. The high-DES group had significantly higher schizotypy scores than the low-DES group. Although both groups also differed with regard to fantasy proneness and, to a lesser extent, traumatic distress, analyses of covariance showed that these variables could not explain group differences in schizotypy. Alternative interpretations of the dissociation-schizotypy link are discussed.

(c) 2005 Elsevier Ltd. All rights reserved.
\end{abstract}

Keywords: Dissociation; Schizotypy; Traumatic intrusions; Fantasy proneness

\section{Introduction}

A number of studies have noted that dissociative symptoms (e.g., feelings of derealization, depersonalization, memory complaints, absorption) overlap with the tendency to report psychotic-like experiences (i.e., schizotypy). For example, Pope and Kwapil (2000) had their undergraduate sample fill out the Dissociative Experiences Questionnaire (DES; Bernstein \& Putnam,

\footnotetext{
* Corresponding author. Tel.: +31 433881 945; fax: +31 433881908 .

E-mail address: h.merckelbach@psychology.unimaas.nl (H. Merckelbach).
} 
1986), which is the standard measure of dissociation, as well as the Chapman scales of psychosis proneness. Several of these scales have proven to be effective predictors of psychosis (e.g., the Perceptual Aberration Scale; PerAb; and the Magical Ideation Scale; MagId). The authors found correlations in the order of 0.44 between dissociation on the one, and schizotypy (as indexed by PerAb and MagId), on the other hand. Using a different measure of schizotypy, Merckelbach, Rassin, and Muris (2000) noted a similar overlap between dissociation and schizotypy in their undergraduate samples $(r=0.64)$. In what seems to be the largest study so far, with two samples including more than 1000 undergraduates, Watson (2001) reported correlations varying from 0.49 to 0.57 between schizotypy and dissociation. Summarizing his own findings, but also clinical data on, for example, dissociative symptoms in schizophrenic patients, this author concluded that "clearly, the association between dissociation and schizotypy is quite robust and is not limited to self-ratings" (Watson, 2001, p. 533).

The question arises as to what may account for the shared variance between dissociation and schizotypy. Three ideas have been put forward in the literature. To begin with, some authors have considered the possibility that shared item content is responsible for the overlap between dissociation and schizotypy. For example, Watson (2001) found that scales measuring dissociation and schizotypy both contain items pertaining to detachment and depersonalization. Obviously, shared item content inflates correlations between constructs. However, Watson (2001) also noted that the overlap between dissociation and schizotypy remains substantial, even when one corrects for the detachment/depersonalization items.

A second interpretation assumes that dissociation and schizotypy are both lower order traits that are nested under the same superordinate trait. Thus, McCrae and Costa (1997) have argued that dissociation, aberrant perception, and magical thinking all reflect the fantasy facet of the big five factor Openness to Experience. Although this interpretation is intuitively plausible, the empirical support for it so far is weak. Indirect evidence comes from studies on transliminality, a concept which refers to some individuals' heightened sensitivity to and preoccupation with imagery, ideation, and affect. These studies reported that absorption-which is an important dimension of dissociation, belief in paranormal phenomena, verbal creativity, and schizotypy are all strongly related to each other (see for a review of this work, Thalbourne \& Houran, 2000; see also Van den Ven \& Merckelbach, 2003). However, in an initial study relying on an unselected sample of undergraduates, we (Merckelbach et al., 2000) found that fantasy proneness does not fully account for the dissociation-schizotypy link.

A third interpretation of the overlap between dissociation and schizotypy emphasizes the traumatic aetiology that may contribute to both constructs (Berenbaum, 1999). The idea is that a history of trauma fosters peculiar perceptions and beliefs, which are tapped by instruments measuring dissociation and schizotypy. Germane to this issue is the renewed interest in how post-traumatic intrusions may lead to a breakdown in reality testing, thereby giving rise to psychotic phenomena like hearing voices. One speculation is that this development only occurs in people who suffer from dissociative symptoms, precisely because these symptoms reflect dysfunctional reality testing abilities (see for a review, Morrison, Frame, \& Larkin, 2003). In line with such formulations, Allen and Coyne (1995) found in their sample of women undergoing inpatient treatment of trauma-related disorders that dissociative symptoms were related most strongly to the schizophrenia scale of the MMPI. In a study that sought to test the traumatic aetiology of the dissociation-schizotypy link in a more direct way, Startup (1999) reported that self-reported 
childhood trauma does not fully explain the variance that dissociation and schizotypy have in common. However, to measure self-reported trauma in his sample, this author employed two yes/no items and therefore, one could argue that his trauma measure was too crude to examine its precise contribution to dissociation and schizotypy. In his sample of Australian adults, Irwin (2001) also looked at the extent to which self-reported trauma might account for the dissociationschizotypy link. His study relied on a well-established, 60-items scale to measure self-reported childhood trauma. Yet, Irwin (2001) too, noted that the dissociation-schizotypy link survives correction for self-reported childhood trauma, leading the author to conclude that "the relationship between dissociative tendencies and schizotypy is not an artefact of childhood abuse" (Irwin, 2001, p. 331).

The aim of the current study was to further explore the link between dissociation and schizotypy and the extent to which fantasy proneness and self-reported trauma might account for this link. Our study deviated from previous work in this domain in four ways. First, we did not address our research question by studying a large, non-clinical sample, but rather selected individuals scoring high or low on dissociation from an undergraduate sample (Kihlstrom, 2005). This was done so as to ensure that we could examine the dissociation-schizotypy link in an extreme group that might be more similar to patient samples, at least as far as dissociation levels are concerned. Secondly, we used a dedicated instrument for measuring fantasy proneness. Thirdly, we employed an instrument tapping current, trauma-related distress as it is conceivable that the dissociation-schizotypy link depends on current traumatic intrusions rather than childhood trauma per se (see also Morrison et al., 2003). This point was inspired by the experimental work of Holmes and Steel (2004), who found that individuals scoring high on schizotypy experience heightened levels of trauma-related intrusions when they have been exposed to emotionally provocative material. Fourthly, in most previous work on dissociation and schizotypy, data were collected during a single test session. Yet, as Council (1993) demonstrated in a thoughtful review, this practice may inflate correlations between measures. To prevent such context effect, we had two separate test sessions.

\section{Method}

\subsection{Participants}

During a mass testing session, 191 undergraduates volunteered to fill out the Dissociative Experiences Scale (DES; Bernstein \& Putnam, 1986). The DES is a self-report scale that asks respondents to indicate the extent to which they experience 28 phenomena that are considered typical manifestations of dissociation (e.g., missing part of a conversation, talking out loud to oneself when alone, not recognizing friends or family members, looking at the world through a fog). Items are scored on $100 \mathrm{~mm}$ Visual Analogue Scales anchored 0 (never) to 100 (always). Total DES scores are obtained by averaging across the 28 items. The full sample consisted of 47 men and 144 women, reflecting the skewed gender distribution of the student population at our faculty. The mean age in this sample was 20.1 years $(\mathrm{SD}=3.76)$. The mean score on the DES was 22 ( $\mathrm{SD}=10.8$; range: 1.9-52.9), while the internal consistency (Cronbach's alpha) for the DES was 0.89 . 
From the total sample, two subgroups were recruited: those scoring in the upper quartile of the DES distribution (DES $>30$ ) and those scoring in the lower quartile of the DES distribution $(\mathrm{DES}<14)$, hereafter denoted as the high- and low-DES groups. Note that the cut-off used for selecting the high-DES group corresponds with recommendations in the clinical literature (e.g., Putnam et al., 1996). Thus, the high-DES group consisted of 47 undergraduates (10 men) with a mean age of 20.4 years $(S D=5.1)$ and the low-DES group consisted of 46 undergraduates (7 men) with a mean age of 19.9 years $(\mathrm{SD}=2.9)$. The two groups did not differ in terms of age $[t(91)<1.0]$ or the proportion of men and women $\left[\chi^{2}(1)<1.0\right]$. The mean DES score of the highand low-DES groups were $37.68(\mathrm{SD}=5.93)$ and $10.02(\mathrm{SD}=3.21)$, respectively $[t(91)=27.88$, $P<0.001]$.

\subsection{Measures}

During a follow-up session one week later, the high- and low-DES group completed the following questionnaires:

\subsubsection{Perceptual Aberration Scale (PerAb; Chapman, Chapman, \& Raulin, 1978)}

The PerAb is a true/false 35 item self-report that asks about perceptual and bodily distortions. Typical items are "I have sometimes had the feeling that my body is decaying inside" and "Sometimes I feel like everything around me is tilting".

\subsubsection{Magical Ideation Scale (MagId; Eckblad \& Chapman, 1983)}

The MagId scale is a 30 item true/false self-report that taps deviant beliefs about causation such as thought transmission and ideas of reference. Sample items are "I have sometimes felt that strangers were reading my mind" and "I have sometimes sensed an evil around me, although I could not see it". After recoding false-keyed items, total PerAb and MagId scores can be obtained by summing the yes-answers. The psychometric qualities of the PerAb and MagId as measures of so-called positive features of schizotypy are excellent and are reviewed by Chapman, Chapman, and Kwapil (1995). Most importantly, large-scale longitudinal studies showed that individuals with elevated PerAb and MagId scores are more likely than controls to develop a psychosis (see also Berenbaum, 1999; Pope \& Kwapil, 2000).

\subsubsection{Creative Experiences Questionnaire (CEQ: Merckelbach, Horselenberg, \& Muris, 2001)}

The CEQ is a dichotomous 25-item questionnaire of fantasy proneness. Some CEQ items allude to the developmental antecedents of fantasy proneness. Other items have to do with intense fantasy and daydreaming or pertain to the consequences of fantasizing. Sample items are: "As a child, I could very easily identify with the main character of a story or movie" and "When I think of something cold, I actually get cold". Yes-answers are summed to obtain a total score (range 025), with higher scores indicating higher levels of fantasy proneness. The CEQ possesses adequate reliability in terms of internal consistency and test-retest stability. Furthermore, the CEQ has predictive validity in the sense that certain categories of individuals who are known to exhibit fantasy prone characteristics (e.g., amateur actors) display higher scores on this scale than do control individuals (see also Sanchez-Bernados \& Avia, 2004). 


\subsubsection{Impact of Event Scale (IES; Horowitz, Wilner, \& Alavarez, 1979)}

The IES is not a retrospective self-report measure of trauma or of post-traumatic stress symptoms, but rather taps current intrusions and avoidance associated with the experience of an aversive event (Joseph, 2000). In the current study, participants were instructed to briefly write down the most aversive life event they had ever experienced and then to complete the IES items with reference to this event. The IES items consists of 15 statements such as "I had dreams about it" and "I tried to remove it from my memory". The statements are rated on 4-point frequency scales pertaining to the past week $(0=$ not at all; $1=$ rarely; $3=$ sometimes, and $5=$ often $)$. Scores are summed to obtain a total IES score. Most studies provide separate scores for the 8-item avoidance factor of the IES and the 7-item intrusions factor of the IES. The psychometric properties of the IES are sound and have been reviewed by Joseph (2000).

\section{Analyses}

Following the approach of Startup (1999) and Watson (2001), we removed items from the Per$\mathrm{Ab}$ and MagId scales that might assess content similar to that tapped by the DES. Similarly, we eliminated those CEQ items that might represent content overlap with the schizotypy scales, notably with items of the MagId scale. ${ }^{1}$ Cronbach's alphas for the modified PerAb, MagId, and CEQ scales were $0.77,0.80$, and 0.73 , respectively. Cronbach' alpha for the IES was 0.91. After these corrections, high- and low-DES groups were compared to each other with regard to PerAb, MagId, CEQ, and IES. Analyses of covariance were conducted so as to establish whether group differences in PerAb and MagId remained significant when the contributions of fantasy proneness (CEQ) and traumatic intrusions and avoidance (IES) were partialled out.

\section{Results}

Table 1 shows mean PerAb, MagId, and CEQ scores as well as mean IES scores of the highand low-DES subgroups. Using Bonferonni corrected $t$-tests with alpha set at $0.05 / 6=0.008$, high- and low-DES groups were compared to each other.

\subsection{Schizotypy}

As can be seen, the high-DES group had higher PerAb and MagId scores than the low-DES group $[t(70.6)=4.48, P<0.001$ and $t(91)=5.44, P<0.001$, respectively]. However, PerAb and MagId scores of the high-DES group came close to the mean scores that have been reported for large Caucasian undergraduate samples in the United States (Kwapil, 1998). The low-DES group had PerAb and MagId scores that were well below these norms, even if one takes the eliminated items into account. In line with this, neither in the high-DES nor in the low-DES subgroups

\footnotetext{
${ }^{1}$ More specifically, we excluded items 3, 11, 12, and 15 from the PerAb scale, and items 3 and 4 from the MagId scale because they all allude to depersonalization/derealization experiences. Furthermore, we eliminated items 21, 22, and 24 from the CEQ because they relate to magical forms of thinking also addressed by the MagId scale.
} 
Table 1

Mean scores on the Perceptual Aberation scale (PerAb), Magical Ideation scale (MagId), Creative Experiences Questionnaire (CEQ), and Impact of Event Scale (IES; with avoidance and intrusion subscales) of low $(n=46)$ and high $(n=47)$ dissociative (DES) participants

\begin{tabular}{lcc}
\hline & Low DES & High DES \\
\hline PerAb $^{\mathrm{a}}$ & $1.94(2.28)$ & $5.11(4.27)$ \\
$\mathrm{MagId}^{\mathrm{a}}$ & $4.48(3.76)$ & $9.28(4.69)$ \\
$\mathrm{CEQ}^{\mathrm{a}}$ & $5.54(3.08)$ & $8.72(3.89)$ \\
$I E S$ & & \\
Total & $14.26(17.07)$ & $23.26(18.21)$ \\
Avoidance & $7.61(9.74)$ & $12.23(10.34)$ \\
Intrusion & $6.65(8.50)$ & $11.02(8.85)$ \\
\hline
\end{tabular}

Standard deviations are given between parentheses.

${ }^{a} t(91)>2.50 ; P<0.01$, two-tailed.

were there participants who had PerAb or MagId scores coming close to or exceeding the cut-offs recommended by Kwapil (1998).

\subsection{Fantasy proneness and trauma-related distress}

As expected, high-DES participants had higher CEQ levels than low-DES participants $[t(91)=4.36, P<0.001]$. Again, the CEQ scores of the high-DES group were very similar to CEQ levels that are typical for large undergraduate samples (e.g., 8.3; Merckelbach et al., 2001), but the low-DES group clearly had a CEQ score below that level. High-DES participants exhibited higher IES scores than low-DES participants, but this difference reached only borderline significance $[t(91)=2.45, P=0.016]$. Similarly, high-DES participants had marginally higher IES avoidance and IES intrusion scores relative to low-DES participants $[t(91)=2.22, P=0.029$ and $t(91)=2.43, P=0.017$, respectively]. In the high-DES group, 13 out of the 47 individuals $(28 \%)$ filled out the IES with reference to the death of a close relative or friend. In the low-DES group, there were 17 out of 46 participants $(38 \%)$ who reported this type of life event. Thus, the two groups did not differ with respect to the frequency with which they reported this type of traumatic event $\left[\chi^{2}(1)=1.41, P=0.23\right]$. Another way to look at the IES data is to use the cut-off criterion of 35 for the total IES score that has been proposed by some authors as the optimal cut-off for detecting trauma-related distress (see also Joseph, 2000). In the high-DES group, there were 12 out of 46 participants $(26 \%)$ with an IES score above this cut-off against 7 out of 46 participants $(15 \%)$ in the low-DES group, a difference that fell short of significance $\left[\chi^{2}(1)=1.52, P=0.22\right]$.

\subsection{Partialling out fantasy proneness and trauma-related distress}

As mentioned before, group differences with regard to PerAb and MagId were significant. The effects sizes $\left(\eta_{p}^{2}\right)$ associated with these differences were 0.18 and 0.25 , respectively. Performing an analysis of variance (ANOVA) on PerAb scores with CEQ and total IES scores as covariates revealed that the difference between high- and low-DES groups remained significant: $\left(F(1,89)=11.05, P=0.001, \eta_{p}^{2}=0.11\right)$. Likewise, an ANOVA on the MagId scores with CEQ 
and IES as covariates showed that the difference between high and low-DES groups remained intact: $\left(F(1,89)=11.41, P=0.001, \eta_{p}^{2}=0.11\right){ }^{2}$

\section{Discussion}

The results of the current study can be summarized as follows. To begin with, in accordance with previous work (Irwin, 2001; Moskowitz, Barker-Collo, \& Ellson, in press; Startup, 1999; Watson, 2001), we found that dissociation and schizotypy go hand in hand. We rigorously eliminated items from our schizotypy measures that might have overlapping content with dissociation items. Also, data were collected on separate occasions to avoid spurious carry-over effects (Council, 1993). Nevertheless, we replicated the dissociation-schizotypy link, indicating that it is a genuine and robust association that cannot be interpreted in terms of spurious overlap in content or context effects.

Secondly, we also found that undergraduates with raised dissociation scores have higher levels of fantasy proneness compared to those with low dissociation scores, a finding that replicates earlier reports in the literature (e.g., Merckelbach et al., 2000, 2001). Thirdly, the difference in trauma-related distress between high and low dissociative individuals was less convincing, with high dissociative individuals scoring only marginally higher on the IES than low dissociative individuals. This finding is difficult to reconcile with the idea that people who score relatively high on schizotypy are vulnerable to the impact of traumatic events and, therefore, suffer more from traumatic intrusions than people low on schizotypy (e.g., Holmes \& Steel, 2004). In the current study, the high dissociative group had considerably higher schizotypy levels than the low dissociative group, but the proportion of individuals with IES scores exceeding the clinical cut-off was similar in both groups. Also, the difference between both groups on the IES intrusion subscale reached only borderline significance. Yet, one could counter that the raised schizotypy levels in the high-DES group were not high enough to demonstrate dysfunctional coping with traumatic intrusions. This is a valid point to which we will return below.

Fourthly and most importantly, we failed to find evidence for the idea that traumatic related distress and/or fantasy proneness might explain the dissociation-schizotypy link. That is to say, high dissociative individuals had significantly raised schizotypy scores compared to low dissociative individuals even when the contribution of fantasy proneness and trauma-related distress was cancelled out with a covariance approach. Thus, the hypothesis that dissociation, schizotypy, and fantasy proneness are all manifestations of "peculiarity" originating from a traumatic aetiology (e.g., Berenbaum, 1999) did not receive any support in our study. It is true that Startup (1999) as well as Irwin (2001) were also unable to find evidence for this "trauma" interpretation. In their studies, however, trauma was defined in a narrow way viz., in terms of childhood trauma. Our results indicate that even when defined in terms of intrusions and avoidance of thoughts about

\footnotetext{
${ }^{2}$ We also performed a linear backward logistic regression, with PerAb, MagId, CEQ, IES as candidate predictors and membership of the high- or low-DES groups as criterion. PerAb, MagId, and CEQ were all maintained in the final step, showing that they were unique predictors (all Wald $\chi^{2}$ s $>2.9$, all $P$ 's $<0.09$ ). IES was removed from the final step, indicating that this variable made no unique contribution to the prediction of high- or low DES scores (Wald $\chi^{2}=0.7$, $P=0.37)$.
} 
aversive events, trauma-related distress does not account for the dissociation-schizotypy link. Taken together, the current findings as well as those of Startup (1999) and Irwin (2001) cast doubts on the idea that schizotypal features are traumatic in origin (but see below).

In our covariance analyses, differences in schizotypy scores between high and low dissociative individuals remained significant, although effect sizes associated with these differences were small (i.e., both $\eta_{p}^{2}$ 's $=0.11$ ). On the other hand, using different measures, different samples, and different analytic strategies, the dissociation-schizotypy link has now been replicated sufficiently often to qualify this link as highly robust (see also Moskowitz et al., in press). If fantasy proneness or trauma-related distress cannot fully account for this link, what is its origin? One possibility that deserves serious consideration is that sleep-related experiences define the common domain of dissociation and schizotypy. In his pioneering work, Watson (2001) noted that both dissociation and schizotypy are related to a broad range of sleep-related phenomena like vivid dreams, recurrent dreams, nightmares, hypnopompic imagery and so on. Giesbrecht and Merckelbach (2004) recently replicated this pattern. Interestingly, Claridge, Clark, and Davis (1997) reported that schizotypy is the single best predictor of nightmare distress and they relate their finding to the idea that schizotypy is characterized by a relative inability to limit the content of consciousness, making it possible for sleep-related material to leak through. A closely related hypothesis is that sleep disturbances in dissociative individuals make these individuals susceptible to cognitive failures, thereby creating overlap with schizotypal features. Tentative support for this comes from pilot work conducted in our lab showing in an undergraduate sample $(N=79)$ that the correlation between DES and schizotypy (as measured with the Schizotypal Personality Scale; Claridge \& Broks, 1984) decreased from $r=0.66(P<0.01)$ to $r=0.22(P=0.05)$ when both fantasy proneness (CEQ) and cognitive failures (as measured with the Cognitive Failures Questionnaire; Broadbent, Cooper, Fitzgerald, \& Parkes, 1982) were held constant statistically. The links between sleep, cognitive failures, dissociation, and schizotypy warrant further research, precisely because they allow for very specific hypotheses. For example, it might well be the case that not trauma per se, but stress-related sleep disturbances produce experiences that define the common domain of dissociation and schizotypy. In line with this speculation, a recent factor analytic study showed that sleep disturbances constitute a separate factor of the IES (Andrews, Shevlin, Troop, \& Joseph, 2004).

Another aspect that future studies should look at is the meaning of low dissociative scores. So far, most authors have framed the dissociation-schizotypy link in clinical terms, stressing the psychopathological version of both constructs (i.e., dissociative disorders and schizophrenia). However, our results demonstrate that even when one selects undergraduates with clinically relevant dissociation scores (i.e., DES scores $>30$ ), their positions on schizotypy scales remain below the clinical cut-offs that predict vulnerability to schizophrenia. Thus, it is conceivable that the low dissociative group has abnormally low schizotypy scores. Interestingly, several authors (e.g., Claridge et al., 1997) have pointed out that schizotypy has its adaptive, positive side. Perhaps, then, the dissociation-schizotypy link is primarily carried by those who score extremely low on these constructs. It would be informative to collect more psychometric data about these groups and to test whether they have certain dysfunctions (e.g., lack of imaginativeness; extreme inhibition) in common.

Two limitations of the current study deserve some comment. First, our study relied on an undergraduate sample. Our findings about the dissociation-schizotypy link cannot be easily gen- 
eralized to clinical populations if only because the schizotypy scores in our sample remained well within the normal range. Secondly and relatedly, it is possible that the relationships among dissociation, schizotypy, and trauma are dynamic in nature. For example, people who are relatively high on schizotypy might have difficulties in controlling trauma-related intrusions only in the first period after the trauma and this might fuel dissociative experiences (e.g., Holmes \& Steel, 2004). It is impossible to test such models with set-ups like the one in the present study. Thus, our understanding of the dissociation-schizotypy link would profit from longitudinal studies.

\section{References}

Allen, J. G., \& Coyne, L. (1995). Dissociation and vulnerability to psychotic experience. Journal of Nervous and Mental Disease, 183, 615-622.

Andrews, L., Shevlin, M., Troop, N., \& Joseph, J. (2004). Multidimensionality of intrusion and avoidance: Alternative factor models of the Impact of Event Scale. Personality and Individual Differences, 36, 431-446.

Berenbaum, H. (1999). Peculiarity and reported childhood maltreatment. Psychiatry, 62, 21-35.

Bernstein, E. M., \& Putnam, F. W. (1986). Development, reliability, and validity, of a dissociation scale. Journal of Nervous and Mental Disease, 174, 727-735.

Broadbent, D. E., Cooper, P. J., Fitzgerald, P. F., \& Parkes, K. R. (1982). The Cognitive Failures Questionnaire (CFQ) and its correlates. British Journal of Clinical Psychology, 21, 1-16.

Chapman, J. P., Chapman, L. J., \& Kwapil, T. R. (1995). Scales for the measurement of schizotypy. In A. Raine, T. Lencz, \& S. Mednick (Eds.), Schizotypal personality (pp. 79-106). New York: Cambridge University Press.

Chapman, L. J., Chapman, J. P., \& Raulin, M. L. (1978). Body-image aberration in schizophrenia. Journal of Abnormal Psychology, 87, 399-407.

Claridge, G., \& Broks, P. (1984). Schizotypy and hemisphere function: Theoretical considerations and the measurement of schizotypy. Personality and Individual Differences, 5, 633-648.

Claridge, G., Clark, K., \& Davis, C. (1997). Nightmares, dreams, and schizotypy. British Journal of Clinical Psychology, 36, 377-386.

Council, J. R. (1993). Context effects in personality research. Current Directions in Psychological Science, 2, 31-34.

Eckblad, M., \& Chapman, L. J. (1983). Magical ideation as an indicator of schizotypy. Journal of Consulting and Clinical Psychology, 51, 215-225.

Giesbrecht, T., \& Merckelbach, H. (2004). Subjective sleep experiences are related to dissociation. Personality and Individual Differences, 37, 1341-1345.

Holmes, E. A., \& Steel, C. (2004). Schizotypy: A vulnerability factor for traumatic intrusions. Journal of Nervous and Mental Disease, 192, 28-34.

Horowitz, M., Wilner, N., \& Alavarez, W. (1979). Impact of Event Scale: A measure of subjective distress. Psychosomatic Medicine, 41, 209-218.

Irwin, H. J. (2001). The relationship between dissociative tendencies and schizotypy: An artefact of childhood trauma. Journal of Clinical Psychology, 57, 331-342.

Joseph, S. (2000). Psychometric evaluation of Horowitz's Impact of Event Scale: A review. Journal of Traumatic Stress, 13, 101-113.

Kihlstrom, J. F. (2005). Dissociative disorders. Annual Review of Clinical Psychology, 10, 1-27.

Kwapil, T. R. (1998). Norms on the Wisconsin psychosis-proneness scales for Caucasian undergraduate students in introductory psychology courses at the University of Wisconsin-Madison. Unpublished lab report.

McCrae, R. R., \& Costa, P. T. (1997). Conceptions and correlates of openness to experience. In R. Hogan, J. A. Johnson, \& S. Briggs (Eds.), Handbook of personality psychology (pp. 825-847). San Diego: Academic Press.

Merckelbach, H., Horselenberg, R., \& Muris, P. (2001). The Creative Experiences Questionnaire (CEQ): A brief selfreport measure of fantasy proneness. Personality and Individual Differences, 31, 987-995.

Merckelbach, H., Rassin, E., \& Muris, P. (2000). Dissociation, schizotypy, and fantasy proneness in undergraduate students. Journal of Nervous and Mental Disease, 188, 428-431. 
Morrison, A. P., Frame, L., \& Larkin, W. (2003). Relationships between trauma and psychosis: A review and integration. British Journal of Clinical Psychology, 42, 331-353.

Moskowitz, A. K., Barker-Collo, S., \& Ellson, L. (in press). Replication of dissociation-psychosis link in New Zealand students and inmates. Journal of Nervous and Mental Disease.

Pope, C. A., \& Kwapil, T. R. (2000). Dissociative experiences in hypothetically psychosis-prone college students. Journal of Nervous and Mental Disease, 188, 530-536.

Putnam, F. W., Carlson, E. B., Ross, C. A., Anderson, G., Clark, P., Torem, M., et al. (1996). Patterns of dissociation in clinical and nonclinical samples. Journal of Nervous and Mental Disease, 184, 673-679.

Sanchez-Bernados, M. L., \& Avia, M. D. (2004). Personality correlates of fantasy proneness among adolescents. Personality and Individual Differences, 37, 1069-1079.

Startup, M. (1999). Schizotypy, dissociative experiences and childhood abuse; relationships among self-report measures. British Journal of Clinical Psychology, 38, 333-344.

Thalbourne, M. A., \& Houran, J. (2000). Transliminality, the mental experience inventory, and tolerance of ambiguity. Personality and Individual Differences, 28, 853-863.

Van den Ven, V., \& Merckelbach, H. (2003). The role of schizotypy, mental imagery, and fantasy proneness in hallucinatory reports of undergraduate students. Personality and Individual Differences, 35, 889-896.

Watson, D. (2001). Dissociations of the night: Individual differences in sleep-related experiences and their relation to dissociation and schizotypy. Journal of Abnormal Psychology, 110, 526-535. 